\title{
Delayed Release Granule Dosage Form
}

National Cancer Institute

\section{Source}

National Cancer Institute. Delayed Release Granule Dosage Form. NCI Thesaurus. Code C42903.

A solid composed of small particles or grains and have been coated with a substance that is designed to impede the immediate release of the active and/or inert ingredient(s) after administration. 